\title{
International core curriculum for capsule endoscopy training courses
}

\section{(ㄷ)(1) $\odot$}

\section{Authors}

Ignacio Fernandez-Urien', Simon Panter ${ }^{2}$, Cristina Carretero $^{3}$, Carolyn Davison ${ }^{2}$, Xavier Dray $^{4}$, Evgeny Fedorov ${ }^{5}$, Richard Makins ${ }^{6}$, Miguel Mascarenhas ${ }^{7}$, Mark McAlindon ${ }^{8}$, Deirdre McNamara ${ }^{9}$, Hansa Palmer ${ }^{10}$, Jean Francoise Rey ${ }^{11}$, Jean Christophe Saurin ${ }^{12}$, Uwe Seitz ${ }^{13}$, Cristiano Spada ${ }^{14}$, Ervin Toth ${ }^{15}$, Felix Wiedbrauck ${ }^{16}$, Martin Keuchel ${ }^{17}$

Institutions

1 Department of Gastroenterology - CHN, Pamplona, Spain

2 Department of Gastroenterology - South Tyneside NHS, South Tyneside, United Kingdom

3 Department of Gastroenterology - University of Navarra, Pamplona, Spain

4 Department of Hepatology and Gastroenterology Saint-Antoine Hospital, Pierre et Marie Curie University \& APHP, Paris, France

5 Department of Abdominal Surgery, Gastroenterology and Endoscopy - Pirogov Russia National Medical University, Moscow University Hospital, Moscow, Russia

6 Department of Gastroenterology - Gloucestershire Hospitals, Gloucester, United Kingdom

7 ManopH \& CUF Oporto Hospitals, Porto, Portugal

8 Department of Gastroenterology - Royal Hallamshire Hospital, Sheffield Teaching Hospitals NHS Foundation Trust, Sheffield, United Kingdom

9 Department of Clinical Medicine - Tallaght Hospital, Trinity College, Dublin, Ireland

10 Digestive Endoscopy Unit - Royal Free Hampstead NHS Trust, London, United Kingdom

11 Institut Arnault Tzanck, Saint Laurent du Var, France

12 Centre Hospitalier Lyon Sud, Pierre Bénite, Lyon, France

13 Department of Internal Medicine 1 - Bergstrasse Medical Center, University Hospital Heidelberg, Heppenheim, Germany

14 Digestive Endoscopy Unit, Fondazione Policlinico Universitario Gemelli, Rome, Italy

15 Department of Gastroenterology - Skåne University Hospital, Lund University, Malmö, Sweden

16 Department of Gastroenterology - Allgemeines Krankenhaus Celle, Celle, Germany

17 Clinic for Internal Medicine, Bethesda Hospital Bergedorf, Hamburg, Germany

submitted 6.2.2017

accepted after revision 10.2.2017
Bibliography

DOI https://doi.org/10.1055/s-0043-106181 |

Endoscopy International Open 2017; 05: E526-E538

(c) Georg Thieme Verlag KG Stuttgart · New York

ISSN 2364-3722

Corresponding author

Ignacio Fernandez-Urien MD, PhD, Department of Gastroenterology - CHN, Pamplona (España), c/ Irunlarrea 3 - 31008 Pamplona (Navarra)

ifurien@yahoo.es

\section{ABSTRACT}

Capsule endoscopy (CE) has become a first-line noninvasive tool for visualisation of the small bowel (SB) and is being increasingly used for investigation of the colon. The European Society of Gastrointestinal Endoscopy (ESGE) guidelines have specified requirements for the clinical applications of CE. However, there are no standardized recommendations yet for CE training courses in Europe. The following suggestions in this curriculum are based on the experience of European CE training courses directors. It is suggested that 12 hours be dedicated for either a small bowel capsule endoscopy (SBCE) or a colon capsule endoscopy (CCE) course with 4 hours for an introductory CCE course delivered in conjunction with SBCE courses. SBCE courses should include state-of-the-art lectures on indications, contraindications, complications, patient management and hardware and software use. Procedural issues require approximately 2 hours. For CCE courses 2.5 hours for theoretical lessons and 3.5 hours for procedural issued are considered appropriate. Hands-on training on reading and interpretation of CE cases using a personal computer (PC) for 1 or 2 delegates is recommended for both SBCE and CCE courses. A total of 6 hours hands-on session- time should be allocated. Cases in a SBCE course should cover SB bleeding, inflammatory bowel diseases (IBD), tumors and variants of normal and cases with various types of polyps covered in CCE courses. Standardization of the description of findings and generation of high-quality reports should be essential parts of the training. Courses should be followed by an assessment of trainees' skills in order to certify readers' competency. 


\section{Introduction}

Since its introduction in 2001 by Iddan et al. [1], CE has become a first-line tool for small bowel SB examination. It has been demonstrated to be an accurate, painless and safe procedure for patients [ $2-4]$. As a result, more than 2 million capsule procedures have been performed worldwide. The excellent performance and acceptability, by both patients and physicians, of wireless technology for the study of SB diseases has led to the development of new capsule endoscopes for the examination of other segments of the gastrointestinal tract such as esophagus and colon [5-8]. Thus, CE has experienced an increasing demand that is anticipated to continue for many years. This demand should be accompanied by the provision of welltrained capsule endoscopists who can read and interpret the videos accurately. As with the vast majority of endoscopic procedures, the need for training in CE has been well documented in the literature and several articles have demonstrated the positive impact of training programs on capsule endoscopists performance [9-13].

Unfortunately, access to training is currently not ideal as demonstrated by a recent survey in United Kingdom (UK) [9]. Although most UK gastroenterology trainees are exposed to, and have an interest in learning CE, only a very small proportion of them have ever reported a CE exam. This situation does not seem likely to change in the future because CE is not included in the gastroenterology training curriculum/programs throughout Europe. Due to its unique characteristics, providing quality CE training alongside service provision is challenging. Some scientific societies, private groups and sponsors in Europe support trainees to learn CE and some of them have developed their own Core Curricula ( $\triangleright$ Table 1 ). However, there is no official consensus on course duration, content, trainee assessment, formal accreditation and quality control.

Considering these deficiencies, a common European Core Curriculum for CE training courses seems necessary, to provide a framework for education that can serve as a platform which can be modified according to prevailing national healthcare systems, clinical and professional needs in each country as it is

- Table 1 Some of the European countries that offer CE training courses.

\begin{tabular}{|l|c|c|}
\hline & SB & Colon \\
\hline England & + & + \\
\hline France & + & + \\
\hline Germany & + & + \\
\hline Ireland & + & - \\
\hline Italy & + & + \\
\hline Portugal & + & + \\
\hline Russia & + & + \\
\hline Spain & + & + \\
\hline Sweden & + & - \\
\hline
\end{tabular}

implemented. Other scientific societies, outside Europe, such as the American Society of Gastrointestinal Endoscopy have developed a SB endoscopy Core Curriculum where some of these requirements were addressed [14]. The Curriculum described here is based on the consensus of European gastroenterologists and endoscopy nurses who are involved in CE and CE training courses. Of note, the final structure of CE training courses and delivery of the curriculum content will depend on local circumstances, organizers availability and the learning objectives of trainees based on the specific requirements for demonstrating competency. Both items may differ among countries.

\section{Aims of the European Curriculum}

The primary aims of this Core Curriculum are:

- To develop a common Core Curriculum for CE training courses across Europe that result in high quality training irrespective of centre, location and practitioner through the setting of training course minimum standards.

- To define requirements for trainers and trainees.

The secondary aims are:

- To expand the awareness of the skills required to undertake CE and the need for training.

- To support individual endoscopy departments, private groups and national societies in developing local or national recommendations for capsule endoscopy training.

- To provide a core framework for trainees' competency assessment and courses formal accreditation/endorsement of courses by national or international societies, official bodies and quality control organizations.

- To improve reading and interpretation of CE.

\section{Methodology}

The development of this Curriculum is based on the consensus of expert practitioners in CE who are involved in CE training courses nationally and in other European countries. The cumulative experience of the working group includes more than 100 SBCE and 60 colon CCE training courses on 4 different CE platforms in 14 European and 10 non-European countries that have been attended by more than 5,000 and 2,000 trainees, respectively. Most of the working group members met in in June 2014. All authors were contacted by e-mail and requested to prepare the following information regarding their training courses:

- Course agenda.

- Pre-course material.

- Post-course material.

- Course syllabus.

- Course quality measurement.

- Trainees' competency measurement.

- Best learning aspects.

During the meeting, all authors presented the mentioned information in slide-based presentations and then, during interactive working group sessions, completed a pre-defined working 
matrix where all CE training courses requirements were noted (Appendix 1). Following the meeting and working in pairs, the authors developed definitive example agendas for SB and CCE training courses (Appendix 2 and Appendix 3). All the information collected in the working matrix as well as in the example agendas for training courses was included in the first draft of the Core Curriculum. Subsequently, all authors were contacted by e-mail for suggestions and corrections. A survey including unresolved questions was also sent to all authors in order to include additional information. Once the final version of the Core Curriculum for training courses in CE was developed, it was sent to all authors in order to receive the final approval.

This Core Curriculum has been developed recognizing the principles of adult education and skills acquisition as described by Brenner [15]. It is recognized that adult trainees have individual expectations based on their previous experience. They expect to be treated as adults and to work hard, to be taught and to learn topics related to their chosen vocation. On the other hand, as described by Brenner, skills acquisition has a five-stage process: novice, beginner, competent, proficient and expert. Since proficiency and expert practice levels take years to develop, this Core Curriculum for CE training courses has been developed to achieve beginner level.

\section{Core curriculum target population}

This Core Curriculum for CE training courses is intended but not exclusively for:

- CE-experienced professionals who are involved in CE training courses.

- CE-experienced gastroenterologists.

- Gastroenterology trainees with or without CE experience.

- Nurses, physician extenders and those professionals exposed to CE.

- Chairmen of gastroenterology departments and endoscopy units.

- Physicians and other professionals involved in gastroenterology training activities.

It has to be noted that this paper differentiates between those professionals who should read the Core Curriculum as they deliver training - Core Curriculum for CE trainer target population - and those professionals who should receive a CE training course - CE training target population.

\section{Course structure}

Most of the CE training courses focus on SB and CCE. Although there is no available information in the literature regarding their optimal structure, they should not differ in learning objectives although changes in the content would be permissible according to local requirements. SB and CCE training courses should be divided in 3 modules or sections:

- The first module of each course should include theoretical lessons such as instructions in the hardware and software for $\mathrm{CE}$, indications, contraindications, complications and their management.
- Table 2 Theoretical lessons to be included in standard CE training courses.

\begin{tabular}{|l|l|l|}
\hline Topic & SBCE course & CCE course \\
\hline CE development & Optional & Optional \\
\hline Equipment & Mandatory & Mandatory \\
\hline Indications & Mandatory & Mandatory \\
\hline Contraindications & Mandatory & Mandatory \\
\hline Complications & Mandatory & Mandatory \\
\hline Patency & Mandatory & Optional \\
\hline Capsule delivery system & Mandatory & Optional \\
\hline Paediatrics & Optional & Optional \\
\hline $\begin{array}{l}\text { National society meetings, } \\
\text { DDW \& UEGW best CE abstracts }\end{array}$ & Optional & Optional \\
\hline $\begin{array}{l}\text { DDW, Digestive Disease Week; UEGW, United European Gastroenterology } \\
\text { Week; CE, capsule endoscopy }\end{array}$ & & \\
\hline
\end{tabular}

- The second course module should include theoretical and practical lessons regarding the procedure - pre-procedure preparation, procedure and post-procedure management, software applications and image interpretation, image classification, size estimation and localization.

- The third and last module of the course should be focused on hands-on sessions. The hands-on training module should be divided in 2 sections based on the objectives to be achieved. The first section should be focused on anatomy and normal findings and the second section should be focused on pathology and abnormal findings.

\section{Course content}

The content of CE training courses should include theoretical, practical and hands-on sessions designed to meet the learning objectives. Some objectives are specific but others are common to both SBCE and CCE training courses and duplication should be avoided if the courses are delivered together. They may be divided in mandatory and optional learning objectives. In the opinion of the working group is that mandatory learning objectives should be included in all CE standard training courses while optional elements may be included or not, depending on course objectives, length and/or learners' requests.

\section{Theoretical lessons}

- Table 2 shows mandatory and optional theoretical lessons to be included in standard CE training courses.

\section{CE Development and Equipment}

The first theory lesson should focus on the development of the CE technology and hardware for CE procedures. Knowing and understanding the principles of wireless technology and how it has been integrated into CE is interesting and may be very helpful in some specific situations such as patient consent and the provision of procedural information and when troubleshooting 
in cases of transmission failure or in the management of capsule retention.

\section{CE Indications}

CE indications should be accompanied by a state-of-the-art lecture including a review of peer-reviewed papers and available international guidelines $[16,17]$ on the subject ( $\vee$ Table 3$)$. Although they can be given together in 1 lecture, it is recommended to cover mandatory indications separately and optional indications together. Optionally, the best abstracts presented at recent main meetings of national societies, DDW and UEGW could also be included in this section if they pertain to relevant clinical practice.

\section{CE Contraindications}

Irrespective of the device used for CE, SB or colon, contraindications (absolute and relative) are broadly similar:

- Swallowing disorders.

- Obstructive dysphagia.

- Suspected or known intestinal obstruction.

- Pregnancy.

- MRI examination planned following CE (until capsule excretion).

- Cardiac pacemakers and other implanted electromechanical devices.

Therefore, when courses are delivered together, it is not necessary to repeat general contraindications in each course. However, some special situations such as abdominal symptoms in IBD patients undergoing SBCE and CCE and co-morbidities such as cardiovascular and renal function in those patients undergoing CE procedures where cleansing agents are used should be always highlighted in the appropriate training course. Where there is the need to discuss the clinical evidence such as in the situation of cardiac pacemakers and/or electromechanical devices there should discussion and opinion based on the available scientific evidence.

\section{CE Complications and Management}

Although CE has been demonstrated to be a very safe procedure, complications may occur. The knowledge of the different complications that may occur - capsule retention or aspiration - and their incidence depending on the indication and the presence of predictive signs or symptoms as well as the availability of different therapeutic approaches will optimize patient management. This session should be accompanied of practical cases showing SB strictures, capsule retentions exemplified using endoscopic and radiologic images, capsule aspirations and their management.

\section{Patency capsule}

The topic of Patency Capsule should be included immediately after CE-related complications. Although this particular product is available from only one manufacturer (Covidien Plc., Dublin, Ireland) the use of such a device to limit retentions-related complications is applicable to all capsule practitioners. The Patency capsule procedure, indications, contraindications, ad-
- Table 3 Indications to be covered in CE training programs based on available guidelines [16,17]

\begin{tabular}{|c|c|c|}
\hline Indications & SBCE course & CCE course \\
\hline OGIB & Mandatory & $\mathrm{N} / \mathrm{A}$ \\
\hline IBD & Mandatory & Optional \\
\hline Celiac disease & Mandatory & $N / A$ \\
\hline GVHD & Optional & $\mathrm{N} / \mathrm{A}$ \\
\hline Polyposis syndromes & Mandatory & $\mathrm{N} / \mathrm{A}$ \\
\hline Tumours & Mandatory & $\mathrm{N} / \mathrm{A}$ \\
\hline NSAIDs enteropathy & Mandatory & $\mathrm{N} / \mathrm{A}$ \\
\hline SB transplantation & Optional & $N / A$ \\
\hline Parasites & Optional & $\mathrm{N} / \mathrm{A}$ \\
\hline Polyps \& CRC & $N / A$ & Mandatory \\
\hline Incomplete colonoscopy & $\mathrm{N} / \mathrm{A}$ & Mandatory \\
\hline Mouth to anus wireless endoscopy & $N / A$ & Optional \\
\hline Undesired colonoscopy & $N / A$ & Optional \\
\hline Contraindicated colonoscopy & $N / A$ & Optional \\
\hline \multicolumn{3}{|c|}{$\begin{array}{l}\text { SBCE, small-bowel capsule endoscopy; CCE, colon capsule endoscopy; OGIB, } \\
\text { obscure gastrointestinal bleeding; IBD, inflammatory bowel disease; GVHD, } \\
\text { graft versus host disease; NSAIDs, non-steroidal anti-inflammatory drugs; } \\
\text { CRC, colorectal cancer; N/A, not applicable }\end{array}$} \\
\hline
\end{tabular}

ministration and capsule detection protocols are the main aspects that should be covered in this lesson. The presentation regarding the Patency capsule topic should be accompanied by some practical cases in order to show its appearance in different segments of the Gl tract and the different levels of disintegration inside the bowel and after excretion (intact versus non-intact Patency capsule).

\section{Pediatrics}

The excellent acceptability and safety profile of the CE has expanded its application into the paediatric population. However, courses to train practitioners to perform CE in this population are beyond the scope of this document. The authors would suggest that issues such as minimum age and weight for $C E$, swallowing difficulties in children, cleansing issues, common indications and clinical outcomes would be the main topics to be covered in a curriculum for the paediatric population.

\section{Capsule endoscopy delivery device}

Although CE swallowing is easy in most cases, sometimes, usually in children and elderly patients and those with non-obstructive dysphagia, physicians have to introduce the capsule in the Gl tract using a tool specially designed for that purpose: the CE delivery device (AdvanCE ${ }^{\circledR}$, US Endoscopy, Mentor, $\mathrm{OH}$, USA). It is easy to use and effective and showing demonstration of use should be mandatory to future CE users. 


\section{Practical lessons}

The following practical topics should be covered in CE training courses. Although they are all common to SBCE and CCE, some of them acquire more importance depending on the gastrointestinal segment to be explored. > Table 4 outlines the topics relating to each stage of the procedure and their specific weight in SBCE and CCE training.

\section{Pre-procedure}

- Information for patients: procedure explanation and informed consent.

- Drugs to be avoided before CE.

- Dietary requirements.

- Cleansing agents administration.

- Antifoaming agents.

\section{Procedure}

- Patients' check-in.

- Regimen selection.

- Pre-ingestion instructions.

- Sensor array/belt placement.

- Capsule ingestion.

- Diet requirements.

- Cleansing \& antifoaming agents administration.

- Prokinetics administration.

- Real time viewing.

- Patients' outcome - i.e: symptoms during CE.

Post-procedure

- Hydration.

- Diet requirements.

- MRI and other procedures.

- Downloading process.

- Capsule excretion.

- Patients' outcome.

- Video reading and interpretation technique.

- Reporting and recommendations.

Although live cases are an excellent option, most of these topics can be taught using didactic videos and either is recommended.

The most important topic in every CE training course should be the video reading and interpretation process. This lesson should begin with a session on how to use basic software followed by the more advanced software applications ( $>$ Table 5). Of note some skills, especially technical, such as software utilisation by participants, improve as the training course progresses as trainees are continuously refining the skills during hands-on sessions. After learning the basics of the software platform, trainers should explain how to read CE videos. SBCE are considered to be easier than CCE videos and this should be reflected on the time spent for each session. At this stage, showing still images of normal and abnormal findings could be beneficial for future readers. Undoubtedly, lesion detection is the main goal of CE. However, lesion characterization, which includes classification, location and size estimation, is also crucial
Table4 Practical topics to be covered in CE training courses.

\begin{tabular}{|c|c|c|c|}
\hline & & $\begin{array}{l}\text { SBCE } \\
\text { course }\end{array}$ & $\begin{array}{l}\text { CCE } \\
\text { course }\end{array}$ \\
\hline \multirow{5}{*}{$\begin{array}{l}\text { Pre- } \\
\text { procedure }\end{array}$} & Procedure explanation & +++ & +++ \\
\hline & Informed consent & +++ & +++ \\
\hline & Drugs to be avoided & +++ & +++ \\
\hline & Diet requirements & +++ & +++ \\
\hline & $\begin{array}{l}\text { Cleansing \& Antifoaming } \\
\text { agents }\end{array}$ & +++ & +++ \\
\hline \multirow[t]{10}{*}{ Procedure } & Patient check-in & +++ & +++ \\
\hline & Regimen selection & + & +++ \\
\hline & Pre-ingestion instructions & +++ & +++ \\
\hline & Sensor array/belt & +++ & ++ \\
\hline & Capsule ingestion & +++ & +++ \\
\hline & Cleansing agents & +++ & +++ \\
\hline & Prokinetics & + & +++ \\
\hline & Diet requirements & +++ & +++ \\
\hline & Real time viewer & + & +++ \\
\hline & Symptoms & +++ & +++ \\
\hline \multirow{7}{*}{$\begin{array}{l}\text { Post- } \\
\text { procedure }\end{array}$} & Hydration & + & +++ \\
\hline & MRI and other procedures & +++ & +++ \\
\hline & Downloading & ++ & ++ \\
\hline & Capsule excretion & +++ & +++ \\
\hline & Outcome & ++ & ++ \\
\hline & Video reading & +++ & +++ \\
\hline & Reporting & +++ & +++ \\
\hline \multicolumn{4}{|c|}{$\begin{array}{l}\text { SBCE, small-bowel c } \\
\text { magnetic resonance } \\
+ \text { Optional } \\
++ \text { Recommended } \\
+++ \text { Mandatory }\end{array}$} \\
\hline
\end{tabular}

and specific sessions covering these topics should be included in training programs.

\section{Hands-on sessions}

Following sessions regarding reading technique, it is time to start with hands-on sessions. SB and CCE video reading is different and this necessitates different training methodology and course design. Course directors are recommended to have a video library with several full videos and video segments containing anatomy, common and uncommon findings and special situations. It is also recommended to categorise the videos as easy, moderate and difficult in order to match difficulty to the trainees' ability and level of acquired skills. 
- Table 5 Basic and advanced software applications to be taught in CE training courses.

\begin{tabular}{|c|c|c|c|}
\hline & & $\begin{array}{l}\text { SBCE } \\
\text { course }\end{array}$ & $\begin{array}{l}\text { CCE } \\
\text { course }\end{array}$ \\
\hline \multirow{13}{*}{$\begin{array}{l}\text { Basic } \\
\text { applications }\end{array}$} & Open video & +++ & +++ \\
\hline & Close Video & +++ & +++ \\
\hline & Open findings & +++ & +++ \\
\hline & Save findings & +++ & +++ \\
\hline & Software interface & +++ & +++ \\
\hline & Reading & +++ & +++ \\
\hline & Capture thumbnail & +++ & +++ \\
\hline & Edit thumbnail & +++ & +++ \\
\hline & Size estimation tools & - & +++ \\
\hline & Localization & +++ & +++ \\
\hline & Reporting & +++ & +++ \\
\hline & Export report & +++ & +++ \\
\hline & Export images & ++ & ++ \\
\hline \multirow{4}{*}{$\begin{array}{l}\text { Advanced } \\
\text { applications }\end{array}$} & Reading modes & ++ & ++ \\
\hline & Suspected blood indicator & + & +++ \\
\hline & Image assembly modes & + & + \\
\hline & Image modification tools & + & + \\
\hline $\begin{array}{l}\text { SBCE, small-bov } \\
\text { MR, magnetic } r\end{array}$ & $\begin{array}{l}\text { apsule endoscopy; CCE, colon } \\
\text { ance imaging }\end{array}$ & sule end & \\
\hline
\end{tabular}

\section{SBC training course}

SBCE videos are usually shorter and easier than CCE videos. This should be reflected in the number of videos to be reviewed during the training course. For each hands-on session, 1 hour for video reading and 30 minutes for discussion should be enough. SBCE hands-on sessions may begin with full videos or specific segments of normal anatomy where the main objective should be detecting the main anatomical landmarks and becoming familiar with the software. Anatomical variation and special situations such as esophageal and gastric retention, incomplete enteroscopy, SB surgery and right hemicolectomy should be commented on and documented. After review of normal videos, trainees should read SB video segments containing common findings such as vascular lesions, Crohn's disease, NSAIDs enteropathy, celiac disease and uncommon findings such as tumours, parasites, foreign bodies and others. Video segments should be short with no more than 10 to 15 minutes reading per case and 10 to 15 minutes for discussion. Trainers should insist that trainees comment on lesion characterisation in line with agreed structured reporting terminology (i.e: CE Standard Terminology [18]). Furthermore, generating a structured report considering the patient's history, results of other examinations and SBCE findings should be an essential part of the training course. Strength and limitations of SBCE should be discussed for each case, considering alternative diagnostic tests and ther- apeutic options in order to provide a balanced recommendation for further patient's management. SBCE hands-on sessions should finish with full videos containing common pathology such as vascular lesions and Crohn's disease, where all the previous learning objectives should be demonstrated. Depending on the cases selected, software applications such as suspected blood indicator and Lewis score could be practised during video segments or full videos visualisation. As a minimum, 2 videos demonstrating normal anatomy, 4 video segments with common and uncommon findings and 2 abnormal full videos are recommended in the SBCE hands-on sessions. However, specific video segments demonstrating the desired abnormalities may replace full videos ( 1 full video $=4$ segments).

\section{CCE training course}

CCE videos are longer and usually much more complex than SBCE and require more time for reading. CCE hands-on sessions should begin with normal video where trainers can explain normal anatomy, landmarks and colon cleansing levels. During hands-on session with normal videos, readers should become confident with the video reading processes - preview, review and report -, evaluation of anatomical landmarks and quality of bowel preparation. Trainers and readers should pay special attention to those conditions where anatomy can change such as colectomy. After normal videos visualisation, video segments with common findings such as polyps should be examined. Video segment selection by course directors should cover the following challenging situations:

- Single frame polyp views.

- 2 or more frames of the same polyp.

- Polyps found by both cameras.

- Polyps only seen in part.

- Flat/serrated polyps.

- Ileocecal valve mimicking a polyp.

Of note the polyp size estimation tool and colon track should be continuously used in CCE hands-on sessions. After video segments visualisation, full videos containing common findings should be read. At this stage, trainers should insist on the correct methodology for video visualisation (i.e. preview, review and report). Normally, 2 normal full videos for the learning of anatomy, 4 video segments with common and uncommon situations and 2 abnormal full videos are recommended in CCE hands-on sessions. As in SBCE training courses, specific video segments may replace full videos.

\section{Report generation}

Video visualization should be followed by the generation of a report of significant findings. The following items should be included:

- Patient demographics.

- Identification of the equipment type.

- Patient preparation.

- Extent of endoscopic visualisation.

- Quality of visualisation.

- Transit times.

- Recording time. 
- Possible limitations.

- Possible complications.

- Findings and characterisation: CEST, size and location.

- Relevant thumbnails.

- Diagnosis.

- Recommendations.

It is crucial for trainees to develop and practise reporting skills as well as video reading and interpretation. Trainees should provide a report after they have completed visualisation of all videos and video segments during hands-on sessions. The trainer should emphasise the importance of an informative and accurate report. Often the referrers for CE may have limited knowledge of CE and limited ability to interpret the report. They may include other specialists as surgeons, general practitioners, cardiologists, etc, who may not understand the reporting language making a clear recommendation of future action mandatory.

\section{Video discussion}

During hands-on sessions, each one of the videos reviewed should be discussed with trainees. After video visualisation, trainers should ask trainees in an open discussion for anatomical landmarks and lesion detection (using time as a marker, i.e: hour, minutes and seconds) and characterisation. At this stage, trainers should try to stimulate trainees' participation in discussions to ensure their attention and improve learning.

\section{Course length}

It is suggested that the course length should be of 1.5 days for SBCE and CCE. However, if SBCE and CCE training courses are given together, the resultant course could be shortened to 2.5 days. There are common sections that need not be repeated such as contraindications, complications and software management. Exceptionally, for basic users, an introductory halfday colon capsule endoscopy called "CCE introductory course" may be added to regular or SBCE courses ( $\triangleright$ Table 6 ). Course length should be flexible according to local circumstances and based on the needs of trainees and organizers availability. The content of the state of the art lectures of both, SB and CCE training courses can be shifted partly into discussion during the hands-on sessions to allow a more interactive teaching. In this case, allocated time has to be adapted accordingly.

\section{SBCE training course}

The duration of the SBCE training course should be 12 hours usually delivered over 1.5 days. However, according to local circumstances and availability the course content may be delivered in one day. SBCE training courses should not be longer than CCE training courses because although there are more topics to be included in the theoretical section, video reading takes less time and is easier. SB videos can be usually read and discussed in less than 1.5 hours per session. Therefore the optimal course distribution should be theoretical lessons (4 hours), procedure lessons ( 2 hours) and hands-on sessions (6 hours).
- Table 6 CCE "introductory” course content.

Theoretical

Equipment for CCE

Procedure \& Preparation

Indications, contraindications and outcomes

Practical

How to read CCE videos?

Images interpretation

Hands-on

Video segments $\times 2$

Full video $\times 1$

CCE, colon capsule endoscopy

\section{CCE training course}

The duration of the colon CE training course should be 12 hours delivered over 1.5 days (when it is given separately). Colon CE training courses should have a different structure compared to SB courses because theoretical topics are fewer and both procedure performance and video reading are more complex. However, the course content may also be delivered in one day. Video reading and discussion may take approximately 1 to 2 hours per video. Therefore the optimal course distribution should be theoretical lessons (2.5 hours), procedure lessons (3.5 hours) and hands-on (6 hours). On introductory CCE courses, the optimal distribution of lessons should be theoreticalpractical ( 2 hours) and hands-on (2 hours) (Appendix 4 ).

It is important to note that the structure, content and length of CE training courses will always depend on trainee's objectives and requirements and also on local circumstances.

\section{Faculty}

The faculty of CE training courses may be divided into 4 groups: course director, theoretical teaching staff, practical teaching staff and hands-on teaching staff. All teachers should be competent in their areas of teaching. Suggested teachers are physicians, endoscopy nurses, and technical experts. Course director, practical teaching staff and hands-on teaching staff should be CE experts. Since there is no available information or evidence regarding the requirements needed to become a CE expert/teacher, this consensus suggests that CE readers should have reviewed at least 300 SB procedures and 200 CCE procedures to become experts. On the other hand, theoretical teaching staff should have experience in CE but they could be nonexpert. In all cases, it is recommended to have experience in optical endoscopy and enteroscopy. However, the ideal scenario would be that all teachers were assessed and formally accredited for their respective roles during CE training courses - i.e: "train the trainers course" -. The optimal ratio between teachers and trainees, especially during hands-on sessions, should be no more than 1:6. 


\section{Course material}

The material to be used in capsule endoscopy courses may be divided in 2 groups: basic or mandatory and optional material.

\section{Basic - material}

- Bag, portfolio or similar containing course program, accreditation, notebook and pen for trainees.

- Slide-based presentations of each theoretical topic. Additional presentations could be helpful in some hands-on sessions.

- Full videos and video segments. They should be selected carefully in order to cover the trainee and course requirements.

- Selected images with normal anatomy, common and uncommon findings.

- Complete CE platform - capsule, data recorder, sensor array/ belt and workstation - and additional devices - capsule endoscopy delivery system - for demonstrations.

- Computers for video reading: this consensus suggests 1 computer with a high-resolution monitor per, at least, 2 trainees.

\section{Optional material}

- Images and videos to be used before or after training courses.

- Capsule endoscopy atlas and other textbooks.

- Selection of review papers and current guidelines.

- Course syllabus.

- Course recordings.

\section{Trainee assessment and certification}

\section{Trainee assesment}

Trainees' assessment before and after CE training courses is essential in order to evaluate readers' progression [19]. The skills to be acquired and then evaluated by assessment tools can be divided in 2 groups: cognitive and hands-on skills ( $\bullet$ Table $\mathbf{7}$ ). Trainee skills should be assessed by validated methods in order to certificate readers' competency. The same method used for trainee assessment should be used to assess trainee progression over the learning curve. Suggested methods for trainee skills assessment are:

- Cognitive skills:

- Oral examination.

- Quiz.

- Web-based.

- Written examination (recommended).

- e-learning.

- Hands-on skills:

- Direct observation (recommended).

- e-learning.

\section{Trainee certification}

After successful assessment, every trainee should receive a certification of competency as a beginner CE reader or certificate of attendance - in line with the certification or credentialing re-
Table 7 Skills to be assessed.

\begin{tabular}{|c|c|}
\hline Skills & Competency \\
\hline Knowledge of equipment & Cognitive \\
\hline Knowledge of indications & Cognitive \\
\hline Accuracy in different clinical scenarios & Cognitive \\
\hline $\begin{array}{l}\text { Recognition and management of compli- } \\
\text { cations }\end{array}$ & Cognitive/Hands-on \\
\hline $\begin{array}{l}\text { Recognition and management of difficult } \\
\text { situations }\end{array}$ & Cognitive/Hands-on \\
\hline Use of CE delivery/retrieval devices & Hands-on \\
\hline Procedure and current variations & Cognitive/Hands-on \\
\hline Anatomy recognition: still images & Hands-on \\
\hline Anatomy recognition: video & Hands-on \\
\hline Pathology recognition: still images & Hands-on \\
\hline Pathology recognition: video & Hands-on \\
\hline $\begin{array}{l}\text { Measuring lesions and use of size estima- } \\
\text { tion tools }\end{array}$ & Hands-on \\
\hline Classifying lesions & Hands-on \\
\hline Locating lesions & Hands-on \\
\hline Use of software* & Hands-on \\
\hline Reading methodology & Hands-on \\
\hline Report elaboration & Hands-on \\
\hline Reading time & Hands-on \\
\hline \multicolumn{2}{|c|}{$\begin{array}{l}\text { * Despite the CE platform used in training courses, except for CapsoCam, } \\
\text { future readers should obtain competency for all CE systems. For Capso- } \\
\text { Cam future users, competency should be obtained in courses using Cap- } \\
\text { soCam's software. }\end{array}$} \\
\hline
\end{tabular}

quirements of the host country. It is important to note that a 3day $C E$ training course is not enough to certificate trainee competency as a competent, proficient and/or expert CE reader. Further training is required in order to reach these objectives. As stated before, CE training assessment tools should be used to assess trainee progression over the learning curve.

\section{Course accreditation, endorsement and quality evaluation}

CE training courses should be accredited by official organisations and endorsed by, at least, one national and/or international scientific society. In order to evaluate and maintain the standards of course quality, both teachers and trainees should complete a satisfaction questionnaire with the option for written comments. All questionnaires should be stored and evaluated at the end of training courses. All criticisms and poor evaluations should be taken into account in order to improve future iterations of the course. On the other hand, it is highly re- 
commendable to be evaluated and accredited by an official quality entity such as Joint Commission International.

\section{Review date}

5 years from publication date.

\section{Competing interests}

The working group was supported by Covidien. Ignacio Fernandez-Urien, Cristina Carretero, Xavier Dray, Ervin Toth, Carolyne Davison and Cristiano Spada received consultancy and lecture fees from Covidien.

\section{References}

[1] Iddan G, Meron G, Glukhovsky A et al. Wireless capsule endoscopy. Nature 2000; 405: 417

[2] Hale MF, Sidhu R, McAlindon ME. Capsule endoscopy: current practice and future directions. World J Gastroenterol 2014; 20: 7752 - 7759

[3] Wang A, Banerjee S, Barth BA et al. ASGE Technology Committee. Wireless capsule endoscopy. Gastrointest Endosc 2013; 78: 805-815

[4] Koulaouzidis A, Rondonotti E, Karargyris A. Small-bowel capsule endoscopy: a ten-point contemporary review. World J Gastroenterol 2013; 19: $3726-3746$

[5] Schoofs N, Devière J, Van Gossum A. PillCam colon capsule endoscopy compared with colonoscopy for colorectal tumor diagnosis: a prospective pilot study. Endoscopy 2006; 38: 971 - 977

[6] Eliakim R, Fireman Z, Gralnek IM et al. Evaluation of the PillCam Colon capsule in the detection of colonic pathology: results of the first multicenter, prospective, comparative study. Endoscopy 2006; 38: $963-970$

[7] Eliakim R, Sharma VK, Yassin K et al. A prospective study of the diagnostic accuracy of PillCam ESO esophageal capsule endoscopy versus conventional upper endoscopy in patients with chronic gastroesophageal reflux diseases. J Clin Gastroenterol 2005; 39: 572-578

[8] Eisen GM, Eliakim R, Zaman A et al. The accuracy of PillCam ESO capsule endoscopy versus conventional upper endoscopy for the diag- nosis of esophageal varices: a prospective three-center pilot study. Endoscopy 2006; 38: $31-35$

[9] Sidhu R, Sakellariou P, McAlindon ME et al. Is formal training necessary for capsule endoscopy? The largest gastroenterology trainee study with controls Dig Liver Dis 2008; 40: 298-302

[10] Postgate A, Tekkis P, Fitzpatrick A et al. The impact of experience on polyp detection and sizing accuracy at capsule endoscopy: implications for training from an animal model study. Endoscopy 2008; 40: $496-501$

[11] Postgate A, Haycock A, Fitzpatrick A et al. How should we train capsule endoscopy? A pilot study of performance changes during a structured capsule endoscopy training program Dig Dis Sci 2009; 54: $1672-1679$

[12] Sidhu R, McAlindon ME, Davison C et al. Training in Capsule Endoscopy: Are We Lagging behind? Gastroenterol Res Pract 2012; 2012: 175248

[13] Rajan E, lyer PG, Oxentenko AS et al. Training in small-bowel capsule endoscopy: assessing and defining competency. Gastrointest Endosc 2013; 78: 617-622

[14] Rajan EA, Pais SA, Degregorio BT. ASGE Training Committee 20112012. et al. Small-bowel endoscopy core curriculum. Gastrointest Endosc 2013; 77: 1-6

[15] Benner P. From novice to expert: Excellence and power in clinical nursing practice. Menlo Park, California: Addison-Wesley Publishing Company; 1984

[16] Pennazio M, Spada C, Eliakim R et al. Small-bowel capsule endoscopy and device-assisted enteroscopy for diagnosis and treatment of small-bowel disorders: European Society of Gastrointestinal Endoscopy (ESGE) Clinical Guideline. Endoscopy 2015; 47: 352-376

[17] Spada C, Hassan C, Galmiche JP et al. Colon capsule endoscopy: European Society of Gastrointestinal Endoscopy (ESGE) Guideline. Endoscopy 2012; 44: 527-536

[18] Korman LY, Delvaux M, Gay G et al. Capsule endoscopy structured terminology (CEST): proposal of a standardized and structured terminology for reporting capsule endoscopy procedures. Endoscopy 2005; 37: $951-959$

[19] Albert ], Humbla O, McAlindon ME et al. A simple evaluation tool (ETCET) indicates increase of diagnostic skills from small bowel capsule endoscopy training courses - a prospective observational European multicenter study. Medicine 2015; 94: e1941 
- Appendix 1 Initial Working Matrix.

\begin{tabular}{|c|c|c|c|c|}
\hline & & SBCETC & $\mathrm{CCE}^{\mathrm{a}}{ }^{\mathrm{T} C}$ & $\mathrm{CCE}^{\mathrm{b} T C}$ \\
\hline \multirow[t]{3}{*}{ Time frame } & Objective & & & \\
\hline & Duration & & & \\
\hline & Theory : Practice & & & \\
\hline \multirow[t]{22}{*}{ Theoretical topics } & Procedure & & & \\
\hline & Alternative tests & & & \\
\hline & Indications & & & \\
\hline & Clinical outcome: OGIB & & & \\
\hline & Clinical outcome: IBD & & & \\
\hline & Clinical outcome: Tumours & & & \\
\hline & Clinical outcome: Other indications & & & \\
\hline & Contraindications & & & \\
\hline & Complications & & & \\
\hline & Patency & & & \\
\hline & Special situations & & & \\
\hline & Pediatrics & & & \\
\hline & Up to date: Literature & & & \\
\hline & Up to date: Congresses & & & \\
\hline & Anatomy & & & \\
\hline & Pathology & & & \\
\hline & CEST & & & \\
\hline & Size/Location & & & \\
\hline & Reporting & & & \\
\hline & Patient recommendations & & & \\
\hline & Reimbursement & & & \\
\hline & Legal issues & & & \\
\hline \multirow[t]{13}{*}{ Hands-on } & Equipment & & & \\
\hline & Demo video & & & \\
\hline & Real patient & & & \\
\hline & Software & & & \\
\hline & How to read & & & \\
\hline & Normal videos & & & \\
\hline & Abnormal videos & & & \\
\hline & Video segments & & & \\
\hline & Full videos & & & \\
\hline & Still images & & & \\
\hline & Difficult cases & & & \\
\hline & Faculty: Trainees & & & \\
\hline & PC: Trainees & & & \\
\hline
\end{tabular}


- Appendix 1 (Continuation)

\begin{tabular}{|c|c|c|c|c|}
\hline & & SBCETC & $\mathrm{CCE}^{\mathrm{a}} \mathrm{TC}$ & $\mathrm{CCE}^{\mathrm{b}} \mathrm{TC}$ \\
\hline \multirow[t]{10}{*}{ Frameworks } & Trainees experience & & & \\
\hline & Participants & & & \\
\hline & Trainers experience & & & \\
\hline & Physician extenders & & & \\
\hline & Pre-read material & & & \\
\hline & Post-read material & & & \\
\hline & Syllabus & & & \\
\hline & Homework & & & \\
\hline & e-learning & & & \\
\hline & Course recording & & & \\
\hline \multirow[t]{4}{*}{ Quality } & Trainee assessment & & & \\
\hline & Endorsements & & & \\
\hline & Accreditations & & & \\
\hline & Train the trainers & & & \\
\hline
\end{tabular}

SBCETC, small bowel capsule endoscopy training course; CCEaTC, "introductory" colon capsule endoscopy training course; CCE'TC, "advanced" colon capsule endoscopy training course; OGIB, obscure gastrointestinal bleeding; CD, Crohn's disease; CEST, capsule endoscopy standard terminology 
- Appendix 2 Example for SBCE training course agenda.

\begin{tabular}{|c|c|}
\hline \multicolumn{2}{|l|}{ Day 1} \\
\hline Time & Topic \\
\hline $08: 00-08: 15$ & Welcome and course overview \\
\hline $08: 15-08: 30$ & History and development \\
\hline 08:30-09:10 & $\begin{array}{l}\text { Material: Capsule, Data Recorder, Sensor Array/ } \\
\text { Belt and Workstation }\end{array}$ \\
\hline 09:10-09:30 & Indications and Contraindications \\
\hline 09:30-09:50 & Complications \\
\hline 09:50-10:10 & State of the art: OGIB \\
\hline $10: 10-10: 40$ & Break (Coffee) \\
\hline $10: 40-11: 00$ & State of the art: IBD \\
\hline $11: 00-11: 20$ & State of the art: Other indications \\
\hline $11: 20-11: 40$ & State of the art: Pediatrics \\
\hline $11: 40-12: 10$ & SBCE: Before, during and after procedure \\
\hline $12: 10-12: 30$ & How to read SBCE \\
\hline $12: 30-14: 00$ & Break (Lunch) \\
\hline $14: 00-14: 30$ & SBCE: Normal and abnormal findings \\
\hline $14: 30-15: 00$ & SBCE: Lesions interpretation \& characterization \\
\hline $15: 00-16: 00$ & Hands-on: Normal anatomy \\
\hline $16: 00-16: 30$ & Break (Coffee) \\
\hline $16: 30-17: 30$ & Hands-on: Normal anatomy \\
\hline $17: 30-18: 00$ & Hands-on: OGIB \& SBI test \\
\hline $18: 00-18: 30$ & Hands-on: IBD \& Lewis score \\
\hline
\end{tabular}

\begin{tabular}{|l|l|}
\hline Day $\mathbf{2}$ & \\
\hline Time & Topic \\
\hline $08: 00-08: 30$ & Hands-on: Other indications \\
\hline $08: 30-10: 00$ & Hands-on: OGIB \\
\hline $10: 00-10: 30$ & Break (Coffee) \\
\hline $10: 30-12: 00$ & Hands-on: IBD \\
\hline $12: 00-12: 30$ & Closing remarks \\
\hline OGIB, obscure gastrointestinal bleeding; IBD, inflammatory bowel disease \\
\hline
\end{tabular}

- Appendix 3 Example for CCE training course agenda.

\begin{tabular}{|c|c|}
\hline \multicolumn{2}{|l|}{ Day 1} \\
\hline Time & Topic \\
\hline $08: 00-08: 15$ & Welcome and course overview \\
\hline $08: 15-08: 30$ & History and development \\
\hline $08: 30-09: 10$ & $\begin{array}{l}\text { Material: Capsule, Data Recorder, Sensor Array/ } \\
\text { Belt and Workstation }\end{array}$ \\
\hline 09:10-09:30 & Indications and Contraindications \\
\hline 09:30-09:50 & Complications \\
\hline 09:50-10:10 & State of the art: Polyps \\
\hline $10: 10-10: 40$ & Break (Coffee) \\
\hline $10: 40-11: 00$ & State of the art: IBD \\
\hline $11: 00-11: 20$ & State of the art: Other indications \\
\hline $11: 20-11: 40$ & State of the art: Paediatrics \\
\hline $11: 40-12: 10$ & CCE: Before, during and after procedure \\
\hline $12: 10-12: 30$ & How to read CCE: Part 1 \\
\hline $12: 30-14: 00$ & Break (Lunch) \\
\hline $14: 00-14: 20$ & How to read CCE: Part 2 \\
\hline $14: 20-14: 40$ & CCE: Normal and abnormal findings \\
\hline $14: 40-16: 00$ & Hands-on: Normal anatomy \\
\hline $16: 00-16: 30$ & Break (Coffee) \\
\hline $16: 30-17: 50$ & Hands-on: Normal anatomy \\
\hline $17: 50-18: 20$ & Hands-on: Polyps \\
\hline $18: 20-18: 50$ & Hands-on: Polyps \\
\hline
\end{tabular}

CCE, colon capsule endoscopy; OGIB, obscure gastrointestinal bleeding; IBD, inflammatory bowel disease

\begin{tabular}{|l|l|}
\hline Day 2 & \\
\hline Time & Topic \\
\hline 08:00-08:30 & Hands-on: IBD \\
\hline $08: 30-10: 00$ & Hands-on: Polyps \\
\hline $10: 00-10: 30$ & Break (Coffee) \\
\hline $10: 30-12: 00$ & Hands-on: Polyps \\
\hline $12: 00-12: 30$ & Closing remarks \\
\hline IBD, inflammatory bowel disease \\
\hline
\end{tabular}


- Appendix 4 Example for CCE "introductory" training course.

\begin{tabular}{|l|l|}
\hline Time & Topic \\
\hline $08: 00-08: 15$ & Welcome and course overview \\
\hline $08: 15-08: 45$ & $\begin{array}{l}\text { Material: Capsule, Data Recorder, Sensor Array/ } \\
\text { Belt and Workstation }\end{array}$ \\
\hline $08: 45-09: 10$ & Procedure \& Preparation \\
\hline $09: 10-09: 35$ & Indications, contraindications \& outcomes \\
\hline $09: 35-10: 15$ & How to read CCE videos? \\
\hline $10: 15-10: 40$ & Break (Coffee) \\
\hline $10: 40-11: 00$ & Images interpretation \\
\hline $11: 00-11: 20$ & Hands-on: Polyps \\
\hline $11: 20-11: 40$ & Hands-on: Polyps \\
\hline $11: 40-13: 00$ & Hands-on: Polyps \\
\hline CCE, colon capsule endoscopy \\
\hline
\end{tabular}

